\title{
Pseudomonas aeruginosa as a Powerful Biofilm Producer and Positive Action of Amikacin Against Isolates From Chronic Wounds
}

\author{
Kashif Rahim, ${ }^{1,}$ Shamim Saleha, ${ }^{2}$ Abdul Basit, ${ }^{3}$ Xudong Zhu, ${ }^{1}$ Iqbal Ahmed, ${ }^{4}$ Liang Huo, ${ }^{1}$ Ping Zhang, \\ Bakhtawar Usman, ${ }^{4}$ Shahzad Munir, ${ }^{5}$ and Octavio Luiz Franco ${ }^{6,7}$ \\ ${ }^{1}$ Beijing Key Laboratory of Genetic Engineering Drug and Biotechnology, Institute of Biochemistry and Biotechnology, College of Life Sciences, Beijing Normal University, \\ Beijing 100875, China \\ ${ }^{2}$ Department of Biotechnology and Genetic Engineering, Kohat University of Science and Technology (KUST), Khyber Pakhtunkhwa Kohat, 26000, Pakistan \\ ${ }^{3}$ College of Biological Sciences, China Agricultural University, Beijing 100193, China \\ ${ }^{4}$ Harbin Veterinary Research Institute, CAAS-Michigan State University Joint Laboratory of Innate Immunity, State Key Lab of VET and Biotech, Chinese Academy of \\ Agricultural Sciences, Harbin, China \\ ${ }^{5}$ Faculty of Plant Protection, Yunnan Agricultural University, Kunming 650201, Yunnan, China \\ ${ }^{6}$ Centro de Análises Proteômicas e Bioquímicas, Programa de Pós-Graduação em Ciências Genômicas e Biotecnologia, Universidade Católica de Brasília, Brazil 70790-160, \\ Brazil \\ ${ }^{7}$ S-Inova Biotech, Programa de Pós-Graduação em Biotecnologia, Universidade Católica Dom Bosco, Campo Grande CEP 79.117-900, Brazil \\ "Corresponding author: Kashif Rahim, Beijing Key Laboratory of Genetic Engineering Drug and Biotechnology, Institute of Biochemistry and Biotechnology, College of Life \\ Sciences, Beijing Normal University, Beijing 100875, China. E-mail: Kashifbangash073@gmail.com
}

Received 2017 July 04; Revised 2017 July 27; Accepted 2017 August 26.

\begin{abstract}
Background: Pseudomonas aeruginosa is a Gram-negative and rod-shaped opportunistic pathogen highly involved in biofilm production in chronic wounds. Biofilms in wounds are the main cause of resistance to multiple antimicrobial agents. This study aimed to identify biofilm-producing bacteria most frequently found in chronic wounds and to examine the association of antibiotic resistance among the isolates.

Objectives: This study was to evaluate the isolation of P. aeruginosa from different types of chronic wounds, as one of the causes of delay in wound healing and biofilm formation, as well as to determine the association of antibiotic resistance among the isolates. Methods: Ninety-one isolates of chronic wounds were obtained from DHQ Hospital KDA District Kohat (Khyber Pakhtunkhwa), Pakistan, from September 2014 to June 2015. Isolates of P. aeruginosa from different types of chronic wounds were biochemically identified and confirmed by molecular identification of one of the conserved genes, algD GDP-mannose dehydrogenase, in P. aeruginosa. Biofilm-forming ability and effects of antibacterial agents were also determined.

Results: The prevalence of diabetic ulcer was found to be more (62.5\%) compared to other types of chronic wounds in patients, and $48.3 \%$ of the isolates were identified as P. aeruginosa. The prevalence of P. aeruginosa in males was found to be higher (56.8\%) than in females, with a statistically non-significant association. Furthermore, biofilm formation was observed in the isolates, so that $79.5 \%$ of $P$. aeruginosa isolates were found to be biofilm producers. Antibacterial drugs were applied to the culture of isolates, showing that $P$. aeruginosa was more resistant to ceftriaxone while amikacin acted as a bactericidal.

Conclusions: From our research, we conclude that delay of wound healing was because of biofilm-producing bacteria found in chronic wounds, which were more resistant to antibiotics because of the ability of biofilm forming. Further, amikacin showed a good activity against $P$. aeruginosa.
\end{abstract}

Keywords: Chronic Wounds, Biofilm Production, Antibacterial Agents, Pseudomonas aeruginosa

\section{Background}

Chronic wounds affect $1-2 \%$ of the population in the entire world, causing persistent morbidity with frequent delay in the healing process and a high recurrence rate (1). Delay of wound healing is becoming one of the major problems imposing heavy burden on public health, and its common factor is the presence of bacterial flora on chronic wounds (2). Pseudomonas aeruginosa is the most com- mon microorganism isolated from chronic wounds, often found as biofilm producer, that acts as a barrier in wound healing and shows resistance to antimicrobial therapy (24). Pseudomonas aeruginosa is a Gram-negative and rodshaped opportunistic pathogen that is a major causative microorganism in wound infections, delaying the wound healing process.

Chronic wounds are classified in different categories, 
such as diabetic foot ulcer (DFU), venous leg ulcers (VLU), pressure ulcer (PU), surgical site infection (SSI), and abscess or trauma ulcers (5). These types of infections are prolonged and become chronic because of bacterial contribution to chronic wounds, on which biofilms develop and increase the normal period of healing $(6,7)$. Biofilm is actually a structured consortium of bacteria and extracellular matrix, which is essential for interconnecting the bacteria and can be composed of polysaccharides, proteins, and extracellular DNA (eDNA) (8). It protects bacterial cells from host defense syatem (9) and impairs healing (10). The existence of biofilms in wounds has been reported in vivo animal data and in vitro models. Sixty percent of chronic wound specimens were characterized as biofilm-containing, whereas only $6 \%$ of acute wounds contained biofilm, indicating biofilms were prevalent in chronic wound samples while relatively rare in samples from acute wounds $(11,12)$.

Microbial involvement in the production of biofilms in chronic wounds was reviewed recently (13). Pseudomonas aeruginosa was the fourth most frequently isolated pathogen in chronic wound infections (8\%), and the seventh leading contributor to bloodstream infections (2 to $6 \%$ ) (14). Epidemiological outcome studies have shown that infections caused by drug-resistant $P$. aeruginos a could be associated with significant increases in morbidity, mortality, the need for surgical intervention, the length of hospital stay and chronic care, and overall cost of treating the infection (15). Chronic wounds are mostly found in diabetic patients, and the mortality rate is $39-80 \%$ in patients after the development of diabetic foot ulcer (16). Pseudomonas aeruginosa exhibits the highest rates of resistance to fluoroquinolones, with resistance to ciprofloxacin and levofloxacin ranging from 20 to $35 \%$. Gentamicin was the least active of the aminoglycosides, with lower rates of resistance being reported for tobramycin and amikacin in most studies $(17,18)$. The present study was designed to discover the prevalence, isolation, and identification of $P$. aeruginosa and its biofilm production in chronic wounds and its resistance to antibiotics in different types of chronic wounds. This study was significant to overcome the problem of the drug of choice in chronic wound patients and to prevent the patients from over use of drugs.

\section{Objectives}

The present study was designed to evaluate the prevalence of $P$. aeruginosa and its antibiotics resistance in different types of chronic wounds. This study was significant to overcome the problem of the drug of choice in chronic wound patients.

\section{Methods}

\subsection{Ethics Statement}

The research was approved by the departmental and University ethics committee No. Kust173638. All data given from patients were full with the agreement of patients and hospital committee.

\subsection{Sampling}

This study was conducted from September 2014 to June 2015. A total of 91 pus or wound swabs from different patients with chronic wound infections including diabetic foot ulcers, non-healing surgical wounds, venous leg ulcers, leg ulcers, and non-healing wounds from an abscess or trauma were collected from different wards (OPD, Medical, Orthopaedic, Burns, Surgical Ward, and Main Operating Theatre) from DHQ Hospital KDA District, Kohat (Khyber Pakhtunkhwa), Pakistan. The isolates of chronic wounds were transported by Cary-Blair Medium (Oxoid Ltd. UK). These wound exudates were immediately transported to the laboratory of the Department of Microbiology, Kohat University of Science and Technology, Pakistan, for further processing.

\subsection{Isolation of P. aeruginosa from Clinical Samples}

Pseudomonas aeruginosa was isolated from each sample as per the provided protocol. Each sample was inoculated onto pseudomonas isolation agar (PIA) followed by identification of $P$. aeruginosa based on Gram staining reaction and biochemical tests such as Oxidase, Motility, Citrate, and Catalase, while negative for Methyl Red, VogesProskauer, Urease and Indole tests, as discussed previously by Dortet et al. (19).

\subsection{Antimicrobial Susceptibility Testing}

The antibiotic resistance patterns of $P$. aeruginosa were assessed using the Kirby-Bauer disk diffusion method, following the recommendations of the clinical and laboratory standard institute (CLSI) (20). Muller-Hinton agar was used to check the resistance of isolates to antibiotic discs. A 0.5 McFarland turbidity standard equivalent bacterial suspension for inoculation was prepared and inoculated. Antibiotic disks (Oxoid Ltd. UK) were applied, and the plate was incubated at $37^{\circ} \mathrm{C}$ for 48 hours. Amikacin $(30 \mu \mathrm{g})$, Augmentin $(30 \mu \mathrm{g})$, Cefepime (30 $\mu \mathrm{g})$, Ceftriaxone $(30 \mu \mathrm{g})$, and Ciprofloxacin $(5 \mu \mathrm{g})$ were used in the present study.

\subsection{Biofilm Assay}

Biofilm formation was determined by plate assay, as previously reported by Freeman et al. (21). Briefly, bacterial isolates were cultured on Congo red agar (CRA agar) plates and then incubated for $24-48$ hours at $37^{\circ} \mathrm{C}$. 


\subsection{PCR (Polymerase Chain Reaction)}

3.6.1. Detection of the algD GDP-Mannose Dehydrogenase Gene

The algD GDP-mannose dehydrogenase gene of $P$. aeruginosa contains 2032 bp (GenBank, AC. No. 400337, Identification No. g45267). The selected primers VIC 1 (5'TTCCCTCGCAGAGAAAACATC3') and VIC2 (5'CCTGGTTGATCAGGTCGATCT 3') were designed to amplify a 520-bp segment of the algD GDP-mannose dehydrogenase gene of $P$. aeruginosa. To assure DNA quality, universal bacterial primers $1 \mathrm{lE}-\mathrm{l} 3 \mathrm{~B}$ were used to target the $16 \mathrm{~S}$ RNA gene of the bacterium (22).

\subsection{Statistical Analysis}

The results were analyzed using SPSS version 16 software. P-values $<0.05$ were considered significant.

\section{Results}

A total of 91 samples were collected from patients with different ulcers, including diabetic ulcers, surgical ulcers, venous leg ulcers, pressure ulcers, and abscess or trauma ulcers (as shown in Table 1). Both genders were included in the study, and more ulcers were observed in males ( $\mathrm{N}$ $=63 ; 69 \%)$ than in females $(\mathrm{N}=28 ; 31 \%)$ with a statistically non-significant association $(\mathrm{P}>0.05)$. The frequency of diabetic ulcers was found to be highest (43.96\%) followed by the frequency of surgical ulcers (19.78\%) (Table 1).

\subsection{Phenotypic Results}

Of the 91 samples collected from different types of wounds, 44 (48.3\%) isolates were identified as P. aeruginosa, which were further confirmed through a series of different biochemical tests. The results showed this bacterium was positive for Oxidase, Motility, Citrate, and Catalase, while negative for Methyl Red, Voges-Proskauer, Urease, and Indole Tests (Table 2). The highest percentage of $P$. aeruginosa (62.5\%) was found in diabetic ulcers, followed by venous leg ulcers (50\%), with a statistically non-significant association (P>0.05) (Table 3).

\subsection{Molecular Identification and Biofilm Production}

PCR was used for further confirmation, targeting the algD gene ( $520 \mathrm{bp}$ ) because it is one of the conserved genes in P. aeruginosa (Figure1). After PCR, the confirmed P. aeruginosa isolates were further subjected to an evaluation of biofilm production, and $79.5 \%$ of samples were found to produce biofilm, while $20.5 \%$ did not produce biofilm (Figure 2).

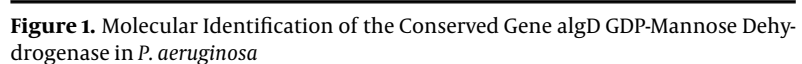
drogenase in $P$. aeruginosa

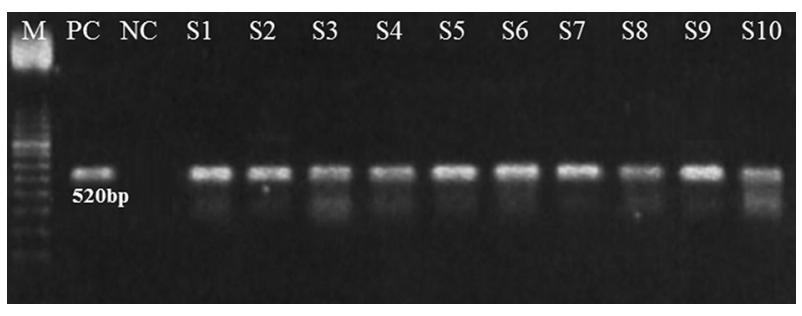

M, Marker (100 bp); PC, Positive control; NC, Negative control; S1-S10, Samples.

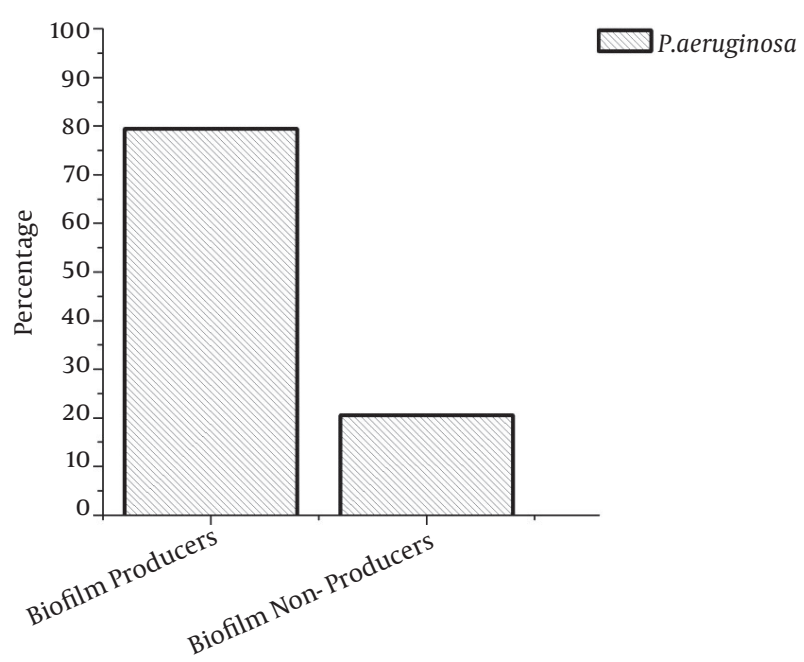

Figure 2. Percentage of Biofilm Producing Isolates and Non-Biofilm Producing Isolates

\subsection{Antibiotic Sensitivity Patterns}

The antibiotic sensitivity patterns of $P$. aeruginosa isolated from clinical specimens were found to be variable. $P$. aeruginosa isolates were more resistant to ceftriaxone (30 $\mu \mathrm{g})$ followed by Augmentin (30 $\mu \mathrm{g})$, ciprofloxacin $(5 \mu \mathrm{g})$, Cefepime $(30 \mu \mathrm{g})$, and amikacin $(30 \mu \mathrm{g})$. The amikacin had a very positive action indicating that $P$. aeruginosa was very less resistant to it. The resistance frequency of the pathogen to different antibiotics is shown in Figure 3.

\section{Discussion}

Rupture of skin due to any accidental cut, bite, or burn is called wound. Every wound has its own period to heal. When the wound does not heal at its specific period, it becomes chronic. The chronicity of wounds depends on many factors, the major of which is bacterial contribution as reviewed by Rahim et al. in 2016 (2). Chronic wounds 
Table 1. Gender-Wise Lesions Percentage and P Value of Different Samples

\begin{tabular}{|c|c|c|c|c|}
\hline Types of Wound & Total $(n=91)$ & Male $(n=63)$ & Female $(n=28)$ & PValue \\
\hline Diabetic ulcers & $40(43.96)$ & $31(49.21)^{\mathrm{a}}$ & $09(32.14)$ & \multirow{6}{*}{$0.657(\mathrm{P}>0.050)$} \\
\hline Surgical ulcers & $18(19.78)$ & $11(17.47)$ & $07(25)$ & \\
\hline Venous leg ulcers & $14(15.38)$ & $09(14.29)$ & $05(17.86)$ & \\
\hline Pressure ulcers & $10(10.99)$ & $06(9.52)$ & $04(14.29)$ & \\
\hline Abscess or trauma ulcers & $9(9.89)$ & $06(9.52)$ & $03(10.71)^{\mathrm{a}}$ & \\
\hline Total & 91 & $63(69)$ & $28(31)$ & \\
\hline
\end{tabular}

${ }^{\mathrm{a}}$ Non-Significant Association between Male and Female $(\mathrm{P}>0.05)$.

Table 2. Biochemical Identification of P. aeruginosa $a^{\mathrm{a}}$

\begin{tabular}{lc}
\hline Biochemical Test & P.aeruginosa \\
\hline Oxidase & + \\
\hline Motility & + \\
\hline Citrate & + \\
M.Red & - \\
\hline V.P & - \\
\hline Urease & - \\
\hline Indole & + \\
\hline Catalase & + \\
\hline a + positive reaction; -, negative reaction.
\end{tabular}

${ }^{a}+$, positive reaction; -, negative reaction.

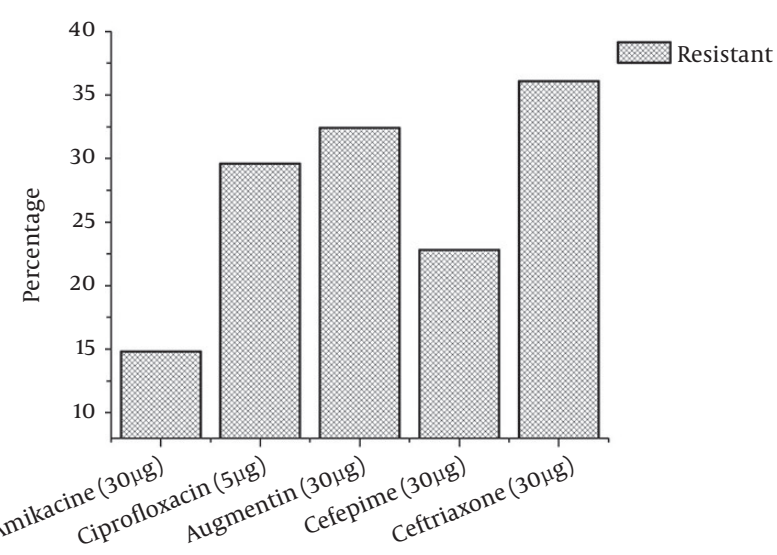

Figure 3. Antibiotic Resistance of Pseudomonas aeruginosa from Chronic Wounds Isolates

contain diverse microbial flora that form biofilm in the wound, further increasing bacterial resistance to drugs. The current findings showed $P$. aeruginosa is present in most of the chronic wounds and the highest prevalence was found in diabetic patients. Similarly, some studies reported $P$. aeruginosa is the most common pathogen in chronic wounds, and found that it is very problematic due to its ability to form biofilms that are highly resistant to antimicrobial agents (23-27).

Recently in a study, diabetic mouse model was used to determine the ability of the opportunistic pathogen, $P$. aeruginosa, to cause biofilm-associated infections, showing the highest risk of chronic infection in the diabetic model (28). It is an opportunistic pathogen, frequently acquired in hospital environments and often is associated with infections in the urinary tracts, burn damage wounds, respiratory infections, and in lungs with cystic fibrosis (29). In this study, $48.3 \%$ of the chronic wounds were found to contain P. aeruginosa. Similarly, the highest prevalence was reported in hospitalized burn patients by Azzopardi et al. (30). Storm-Versloot et al. (31) also reported even a higher prevalence, with $52.2 \%$ of chronic wounds presenting this bacterium.

Biofilm production ability of microbial communities makes threats in case of wounds infection because immune system access to biofilm is very limited due to a thick layer. According to the current research, $79.5 \%$ of the $P$. aeruginosa isolates were found to be biofilm producers, whereas biofilm formation of P. aeruginosa was also found most prevalent in clinical isolates and had high associations in chronic wound infections (32). In our study, diabetic ulcers were found to be frequent, representing $43.96 \%$ of the chronic wounds. In diabetic ulcers, the patient's condition as well as the environment may act together with other associated problems in the patient to affect the ecology of the wound (33). Diabetic patients always have decreased immune response with a lower resistance to $\mathrm{mi}$ crobial infections. Diabetic foot infection is the most common and severe complication in patients who suffer from diabetes mellitus. In this type of patients, wounds mostly are contaminated significantly by non-replicating bacteria (34). During the treatment of chronic wounds, different groups of antibiotics are used usually. 
Table 3. Isolation of P. aeruginosa from Different Ulcers

\begin{tabular}{|c|c|c|c|c|}
\hline \multirow[t]{2}{*}{ Types of Wounds } & \multicolumn{3}{|c|}{ P. aeruginosa } & \multirow[t]{2}{*}{ P Value } \\
\hline & Positive & Negative & Percentage & \\
\hline Diabetic ulcers & 25 & 15 & 62.5 & \multirow{6}{*}{$0.1042(\mathrm{P}>0.05)$} \\
\hline Surgical ulcers & 07 & 11 & 38.8 & \\
\hline Venous leg ulcers & 07 & 07 & 50 & \\
\hline Pressure ulcers & 03 & 07 & 27.2 & \\
\hline Abscess or trauma ulcers & 02 & 07 & 22.2 & \\
\hline Total (\%) & 44 & 47 & 48.3 & \\
\hline
\end{tabular}

Treatment failure and increasing prevalence rate of infection in chronic wounds show the ability of microbial communities to resist the antibiotics. Based on the current findings, isolates from chronic wounds showed less resistance to amikacin and higher resistance to other antibiotics as shown in Figure 1. Isolates from chronic wounds showed the highest level of resistance to the antibiotic. Similarly, Moore and Flaws (35) reported that P. aeruginosa is highly resistant to antibiotics.

\section{Conclusions}

Due to the biofilm production ability of P. aeruginosa, it becomes more virulent and cannot eradicate easily from chronic wounds. Major reasons for antibiotic resistance are over use of antibiotics in daily life. This is one of the basic burdens on public health.

\section{Acknowledgments}

We are very grateful to DHQ hospital, Kohat, for allowing us to take samples, and especially to Dr. Muhammad Qasim and Dr. Hazir-ur-Rahman, who helped with this research work.

\section{Footnotes}

Authors Contribution: Kashif Rahim conducted all the experiments supervised by Shamim Saleha, and the others helped in experiments and writing of the manuscript. Octavio Luiz Franco finalized the manuscript.

Financial Disclosure: The authors declare that no competing financial interests exist.

Conflict of Interest: The authors declare no conflict of interest.

\section{References}

1. Gjodsbol K, Christensen JJ, Karlsmark T, Jorgensen B, Klein BM, Krogfelt KA. Multiple bacterial species reside in chronic wounds: a longitudinal study. Int Wound J. 2006;3(3):225-31. doi: 10.1111/j.1742481X.2006.00159.x. [PubMed: 16984578].

2. Davis R, Brown PD. Multiple antibiotic resistance index, fitness and virulence potential in respiratory Pseudomonas aeruginosa from Jamaica. J Med Microbiol. 2016 doi: 10.1099/jmm.0.000229. [PubMed: 26860081].

3. Mantero M, Gramegna A, Pizzamiglio G, D’Adda A, Tarsia P, Blasi F. Once daily aerosolised tobramycin in adult patients with cystic fibrosis in the management of Pseudomonas aeruginosa chronic infection. Multidiscip Respir Med. 2017;12:2. doi: 10.1186/s40248-016-0083-y. [PubMed: 28184305].

4. Hoiby N, Bjarnsholt T, Givskov M, Molin S, Ciofu O. Antibiotic resistance of bacterial biofilms. Int J Antimicrob Agents. 2010;35(4):322-32. doi: 10.1016/j.ijantimicag.2009.12.011. [PubMed: 20149602].

5. Rahim K, Saleha S, Zhu X, Huo L, Basit A, Franco OL. Bacterial Contribution in Chronicity of Wounds. Microb Ecol. 2017;73(3):710-21. doi: 10.1007/s00248-016-0867-9. [PubMed: 27742997].

6. Dowd SE, Sun Y, Secor PR, Rhoads DD, Wolcott BM, James GA, et al. Survey of bacterial diversity in chronic wounds using pyrosequencing, DGGE, and full ribosome shotgun sequencing. BMC Microbiol. 2008;8:43. doi: 10.1186/1471-2180-8-43. [PubMed: 18325110].

7. Oates JL. Genome sequencing of two chronic wound isolated pseudomonas aeruginosa strains to understand adaptation and antibiotic resistance. ; 2015.

8. Whitchurch CB, Tolker-Nielsen T, Ragas PC, Mattick JS. Extracellular DNA required for bacterial biofilm formation. Science. 2002;295(5559):1487. doi: 10.1126/science.295.5559.1487. [PubMed: $11859186]$.

9. Harmsen M, Yang L, Pamp SJ, Tolker-Nielsen T. An update on Pseudomonas aeruginosa biofilm formation, tolerance, and dispersal. FEMS Immunol Med Microbiol. 2010;59(3):253-68. doi: 10.1111/j.1574695X.2010.00690.x. [PubMed: 20497222].

10. Nithya C, Begum MF, Pandian SK. Marine bacterial isolates inhibit biofilm formation and disrupt mature biofilms of Pseudomonas aeruginosa PAO1. Appl Microbiol Biotechnol. 2010;88(1):341-58. doi: 10.1007/s00253-010-2777-y. [PubMed: 20665017].

11. Malone M, Swanson T. Biofilm-based wound care: the importance of debridement in biofilm treatment strategies. Br J Community Nurs. 2017;22(Sup6):S20-5. doi: 10.12968/bjen.2017.22.Sup6.S20. [PubMed: 28570133].

12. James GA, Swogger E, Wolcott R, Pulcini E, Secor P, Sestrich J, et al. Biofilms in chronic wounds. Wound Repair Regen. 2008;16(1):37-44. doi: 10.1111/j.1524-475X.2007.00321.x. [PubMed: 18086294]. 
13. Malone M, Bjarnsholt T, McBain AJ, James GA, Stoodley P, Leaper D, et al. The prevalence of biofilms in chronic wounds: a systematic review and meta-analysis of published data. J Wound Care. 2017;26(1):20-5. doi: 10.12968/jowc.2017.26.1.20. [PubMed: 28103163].

14. Gaynes R, Edwards JR, National Nosocomial Infections Surveillance S. Overview of nosocomial infections caused by gram-negative bacilli. Clin Infect Dis. 2005;41(6):848-54. doi: 10.1086/432803. [PubMed: 16107985].

15. Aloush V, Navon-Venezia S, Seigman-Igra Y, Cabili S, Carmeli Y. Multidrug-resistant Pseudomonas aeruginosa: risk factors and clinical impact. Antimicrob Agents Chemother. 2006;50(1):43-8. doi: 10.1128/AAC.50.1.43-48.2006. [PubMed: 16377665].

16. Rayber GE. In: The diabetic foot. Bowker JH, Pfeifer MA, editors. St louis, Missouri: Mosby Inc; 2001.pp.13-32.Epidemiology of foot ulcers and amputations in the diabetic foot.

17. Flamm RK, Weaver MK, Thornsberry C, Jones ME, Karlowsky JA, Sahm DF. Factors associated with relative rates of antibiotic resistance in Pseudomonas aeruginosa isolates tested in clinical laboratories in the United States from 1999 to 2002. Antimicrob Agents Chemother. 2004;48(7):2431-6. doi: 10.1128/AAC.48.7.2431-2436.2004. [PubMed: 15215091].

18. Obritsch MD, Fish DN, MacLaren R, Jung R. National surveillance of antimicrobial resistance in Pseudomonas aeruginosa isolates obtained from intensive care unit patients from 1993 to 2002. Antimicrob Agents Chemother. 2004;48(12):4606-10. doi: 10.1128/AAC.48.12.46064610.2004. [PubMed:15561832].

19. Dortet L, Poirel L, Nordmann P. Rapid identification of carbapenemase types in Enterobacteriaceae and Pseudomonas spp. by using a biochemical test. Antimicrob Agents Chemother. 2012;56(12):6437-40. doi:10.1128/AAC.01395-12. [PubMed: 23070158].

20. Sneath PH, Mair NS, Sharpe ME. JG Holt Bergey's Manual of Systematic Bacteriology, 2. Baltimore: Williams and Wilkins; 1986.

21. Freeman DJ, Falkiner FR, Keane CT. New method for detecting slime production by coagulase negative staphylococci. J Clin Pathol. 1989;42(8):872-4. [PubMed: 2475530].

22. da Silva Filho LV, Levi JE, Oda Bento CN, da Silva Ramos SR, Rozov T. PCR identification of Pseudomonas aeruginosa and direct detection in clinical samples from cystic fibrosis patients. J Med Microbiol. 1999;48(4):357-61. doi: 10.1099/00222615-48-4-357. [PubMed: 10509477].

23. Ammons MC, Ward LS, Fisher ST, Wolcott RD, James GA. In vitro susceptibility of established biofilms composed of a clinical wound isolate of Pseudomonas aeruginosa treated with lactoferrin and xylitol. Int J Antimicrob Agents. 2009;33(3):230-6. doi: 10.1016/j.ijantimicag.2008.08.013. [PubMed: 18977641].

24. Bjarnsholt T, Kirketerp-Moller K, Jensen PO, Madsen KG, Phipps R, Krogfelt $\mathrm{K}$, et al. Why chronic wounds will not heal: a novel hy- pothesis. Wound Repair Regen. 2008;16(1):2-10. doi: 10.1111/j.1524475X.2007.00283.x. [PubMed: 18211573].

25. Kirketerp-Moller K, Jensen PO, Fazli M, Madsen KG, Pedersen J, Moser $\mathrm{C}$, et al. Distribution, organization, and ecology of bacteria in chronic wounds. J Clin Microbiol. 2008;46(8):2717-22. doi: 10.1128/JCM.0050108. [PubMed: 18508940$]$.

26. Thomsen TR, Aasholm MS, Rudkjobing VB, Saunders AM, Bjarnsholt T, Givskov M, et al. The bacteriology of chronic venous leg ulcer examined by culture-independent molecular methods. Wound Repair Regen. 2010;18(1):38-49. doi: 10.1111/j.1524-475X.2009.00561.x. [PubMed: 20082680].

27. Madigan MT, Martinko JM, Parker J. Brock biology of microorganisms. 11. Prentice hall Upper Saddle River, NJ;1997.

28. Watters C, DeLeon K, Trivedi U, Griswold JA, Lyte M, Hampel KJ, et al. Pseudomonas aeruginosa biofilms perturb wound resolution and antibiotic tolerance in diabetic mice. Med Microbiol Immunol. 2013;202(2):131-41. doi: 10.1007/s00430-012-0277-7. [PubMed: 23007678].

29. Driscoll JA, Brody SL, Kollef MH. The epidemiology, pathogenesis and treatment of Pseudomonas aeruginosa infections. Drugs. 2007;67(3):351-68. [PubMed: 17335295].

30. Azzopardi EA, Azzopardi E, Camilleri L, Villapalos J, Boyce DE, Dziewulski P, et al. Gram negative wound infection in hospitalised adult burn patients-systematic review and metanalysis. PLoS One. 2014;9(4):e95042. doi: 10.1371/journal.pone.0095042. [PubMed: 24751699].

31. Storm-Versloot MN, Vos CG, Ubbink DT, Vermeulen H. Topical silver for preventing wound infection. Cochrane Database Syst Rev. 2010(3):CD006478. doi: 10.1002/14651858.CD006478.pub2. [PubMed: 20238345].

32. Sanchez CJ, Mende K, Beckius ML, Akers KS, Romano DR, Wenke JC, et al. Biofilm formation by clinical isolates and the implications in chronic infections. BMC Infect Dis. 2013;13:47. doi: 10.1186/1471-2334-1347. [PubMed: 23356488].

33. Dowd SE, Wolcott RD, Sun Y, McKeehan T, Smith E, Rhoads D Polymicrobial nature of chronic diabetic foot ulcer biofilm infections determined using bacterial tag encoded FLX amplicon pyrosequencing (bTEFAP). PLoS One. 2008;3(10):e3326. doi: 10.1371/journal.pone.0003326. [PubMed:18833331].

34. Baffoni M, Bessa LJ, Grande R, Di Giulio M, Mongelli M, Ciarelli $A$, et al. Laser irradiation effect on Staphylococcus aureus and Pseudomonas aeruginosa biofilms isolated from venous leg ulcer. Int Wound J. 2012;9(5):517-24. doi: 10.1111/j.1742-481X.2011.00910.x. [PubMed: 22182280].

35. Moore NM, Flaws ML. Antimicrobial resistance mechanisms in Pseudomonas aeruginosa. Clin Lab Sci. 2011;24(1):47-51. [PubMed: 21404965] 